\title{
Integrated Nanozero Valent Iron and Biosurfactant-Aided Remediation of PCB-Contaminated Soil
}

\author{
He Zhang, Baiyu Zhang, and Bo Liu \\ Northern Region Persistent Organic Pollution Control (NRPOP) Laboratory, Faculty of Engineering and Applied Science, \\ Memorial University, St. John's, NL, Canada A1B 3X5
}

Correspondence should be addressed to Baiyu Zhang; bzhang@mun.ca

Received 24 February 2016; Accepted 28 April 2016

Academic Editor: Ezio Ranieri

Copyright (C) 2016 He Zhang et al. This is an open access article distributed under the Creative Commons Attribution License, which permits unrestricted use, distribution, and reproduction in any medium, provided the original work is properly cited.

\begin{abstract}
Polychlorobiphenyls (PCBs) have been identified as environmental hazards for years. Due to historical issues, a considerable amount of PCBs was released deep underground in Canada. In this research, a nanoscale zero valent iron- (nZVI-) aided dechlorination followed by biosurfactant enhanced soil washing method was developed to remove PCBs from soil. During nZVIaided dechlorination, the effects of nZVI dosage, initial $\mathrm{pH}$ level, and temperature were evaluated, respectively. Five levels of nZVI dosage and two levels of initial $\mathrm{pH}$ were experimented to evaluate the PCB dechlorination rate. Additionally, the temperature changes could positively influence the dechlorination process. In soil washing, the presence of nanoiron particles played a key role in PCB removal. The crude biosurfactant was produced using a bacterial stain isolated from the Atlantic Ocean and was applied for soil washing. The study has led to a promising technology for PCB-contaminated soil remediation.
\end{abstract}

\section{Introduction}

As family members of chlorinated hydrocarbons, polychlorinated biphenyls (PCBs) are a group of manmade chemicals which were first synthesized in 1881 and commercialized in North American industries from the 1930s to the late 1970s [1-3]. Although never manufactured in Canada, PCBs have been imported and widely used in hundreds of industrial and commercial applications (e.g., electric insulators, plasticizers for adhesives, lubricants, hydraulic fluids, sealants, cutting oils, and flame retardants) due to their nonflammability and electrical insulating properties as well as chemical stability at high temperature and low vapor pressure $[4,5]$.

These compounds did not exist in nature. After synthesis, they were found in the environment in 1966 [6]. Since then, PCBs were so widely discovered in the global environment where trace concentrations were detected even in remote areas such as the atmosphere of the Arctic and the Antarctic and the hydrosphere and biosphere [3].

Exposure to PCBs can lead to cancer and a variety of serious noncancer health effects on different systems. Hence, Canada restricted the use of PCBs in 1977 and prohibited the import of PCBs in $1980[7,8]$. Current legislation allows PCBcontaining electrical equipment manufactured before 1980 to remain in use until the end of their service life; however, strict maintenance and handling procedures and regulatory control by governments are required to prevent any release into the environment [2]. As specified in the Federal Contaminated Sites Inventory (FCSI), PCB-contaminated sites are recognized in all the provinces and territories throughout Canada. In fact, most of these sites are contaminated as a consequence of inappropriate handling, storage, and disposal [4].

Federal and provincial governments, as well as associated industries, have been obliged to endeavour research efforts and provide financial support for site identification, remediation, and long term monitoring. Since 1994, the number of PCB-contaminated sites has been reduced under provincial jurisdiction. However, the large amount of remaining untreated sites and the revived problems in the treated sites are still risking the provincial ecosystems and environment. The preliminary assessment process estimates the volume of free products could be 15-20 million litres and the majority of the PCB pollutants are deep underground [9]. Industries have been making efforts to solve individual problems and/or 
processes related to site remediation practices during the past years. Among the existing technologies, incineration and landfill were frequently applied. However, the remediation was usually long term and costly, and the exhaust could cause secondary pollution [10]. There is a shortage of effective technologies to treat and remove PCB contaminants from soils and sediments. This situation has hindered the efforts to effectively protect the environments of this region. Therefore, it is desired that innovative technologies that can enhance the efficiencies and effectiveness of remediation of PCBcontaminated sites be developed within Canadian context.

Nanoscale zero valent iron (nZVI) particles have been widely applied in removing chloridized hydrocarbons including PCBs due to their extraordinarily reductive property $[11,12]$. Some recent research has revealed that nZVI particles are effective in the transformation of a large variety of environmental contaminants, while they are inexpensive and nontoxic [13]. nZVI may chemically reduce PCBs effectively through reductive dechlorination, allowing the pollutant to be readily biodegradable after treatment. Studies by Mueller and Nowack [14] have shown that nZVI as a reactive barrier is very effective in the reduction of chlorinated methane, chlorinated ethane, chlorinated benzenes, and other polychlorinated hydrocarbons. Varma [15] has successfully applied nZVI in soil columns with a wide range of plant phenols as additives, which allows greater access to the contaminant and creates less hazardous waste in the manufacturing process. The application of nZVI to the contaminated soil could enhance the dechlorination of PCBs; nevertheless, higher chlorinated biphenyls require much longer time than lower ones to be completely dechlorinated. Biphenyls as the final product of PCBs are still environmental and health hazards which need further treatment. A time-saving technology that can completely degrade PCBs in the soils or remove PCBs from the soils is consequently in demand.

Soil washing has been applied to effectively and rapidly remove soil contaminants. This technology provides a closed system that remains unaffected by external conditions [16], and the system permits the control of the conditions (e.g., additive concentration) under which the soil particles are treated [17]. Soil washing is cost-effective and often combined with other remediation technologies. Solvents are critical for soil washing and selected on the basis of their ability to solubilize specific contaminants and on their environmental and health effects [18]. However, although soil washing can provide a high efficiency when extracting contaminants from the soil, there are still some limitations when dealing with PCBs. One of the constraints is that PCBs have low water solubility-0.0027-0.42 ng/L [19]; they are soluble in organic or hydrocarbon solvents, oils, and fats. Moreover, PCBs tend to stay in the soils instead of flushing with solvents or water. Since high-chlorinated biphenyls are less water-soluble than low-chlorinated ones and PCBs often preferentially adhere to the clay or silt fraction of the soils [20], removal of the high-chlorinated biphenyls in clayey or silty soils will become extremely difficult. It is thus very hard to find an appropriate washing solvent for PCB removal from soil.

Biosurfactants are surface-active compounds from biological sources, usually extracellular, produced by bacteria, yeast, or fungi [21]. Compared with chemical surfactants, biosurfactants have been applied in contaminated soil remediation due to the advantages of low toxicity, high specificity, biodegradability and biocompatibility, and functionality under extreme conditions [22-24]. Applying biosurfactants as the solvents in soil washing systems to treat PCBcontaminated soil has the following benefits: (1) it would effectively enhance solubilization of PCBs in the washing solution, leading to increased removal efficiency; and (2) it could stimulate microbial activity that enhances biodegradation of PCBs which are soil bound [24]. However, although the application of biosurfactants with soil washing can significantly increase the solubility of PCBs that increase the extraction efficiency [23], PCBs that dissolved in the washing solution need to be further treated before being released into the environment. As persistent organic pollutants, PCBs are hard to degrade, leading to costly and complex posttreatment processes before discharge [24]. In addition, larger volumes of washing solution may be needed when additives like biosurfactants are used. A high biosurfactant concentration in the washing solution can cause foaming problems and inhibit the ability to remove PCBs from the soil [25]. Increasing attention has been received on the combination of different technologies in recent years. These technologies can be applied in sequence to enhance the cost effectiveness [26]. Effective dechlorination approaches which can be integrated with soil washing and facilitate PCB biodegradation are thus desired.

This study is essential for the applications to the removal of PCBs from soil. It aims to combine nanotechnology and an existing soil washing system with biosurfactants as the solvent to better clean up the PCB-contaminated sites. Since higher chlorinated biphenyls have lower aqueous solubilities than lower chlorinated ones, biosurfactant-aided soil washing could have higher removal efficiencies on lower chlorinated biphenyls than that on higher ones [27]. Therefore, the sequence of the combined technologies would be better started with nZVI-aided dechlorination and followed by biosurfactant-aided soil washing. Through the experimental study of various factors (one factor at a time) affecting PCB dechlorination (nZVI dosage, $\mathrm{pH}$, and temperature) and soil washing effectiveness (nZVI and concentrations of biosurfactant solution), the research output is expected to generate environmentally friendly and economically/technically feasible solutions for helping solve the challenging site contamination problem in Canada.

\section{Materials and Methods}

2.1. Materials. The materials were as follows:

(1) Soil: soil used in this research was fine sands purchased from a local company City Sand \& Gravel Ltd., St. John's, NL.

(2) PCBs: commercial PCB products are no longer manufactured and traded in Canada. The contaminants used in this study were in the form of transformer oil obtained from local industry. The overall PCB 
concentration in the transformer oil was measured to be 120 ppm by a commercial lab.

(3) nZVI particles: nanofer star, one kind of commercialized air-stable nanoiron powders, was purchased from NANO IRON, sro, Czech Republic.

(4) Biosurfactants: a Bacillus sp. bacterial strain isolated from the Atlantic Ocean [28] was cultured to generate biosurfactants in the NRPOP Lab. After culturing and extraction, the crude biosurfactants were separated from the media and characterized through testing the critical micelle concentration (CMC). These crude biosurfactants were then ready for use.

(5) Other materials and chemicals: anhydrous sodium sulfate (ACS reagent); hexane (CHROMASOLV ${ }^{\circledR}$ Plus, for HPLC, $\geq 95 \%$ ); acetone (CHROMASOLV Plus, for HPLC, $\geq 99.9 \%$ ); Supelclean $^{\mathrm{TM}}$ Sulfoxide SPE Tube (PE frit, bed wt. $3 \mathrm{~g}$, volume $6 \mathrm{~mL}$ ); biphenyl- $\mathrm{d}_{10}$ (99 atom\% D); EPA 525, 525.1 PCB Mix (500 $\mu \mathrm{g}$ / $\mathrm{mL}$ each component in hexane, analytical standard); barium chloride dihydrate $\left(\mathrm{BaCl}_{2} \cdot 2 \mathrm{H}_{2} \mathrm{O}\right.$, ACS reagent, $\geq 99.0 \%$ ); magnesium sulfate heptahydrate $\left(\mathrm{MgSO}_{4} \cdot 7 \mathrm{H}_{2} \mathrm{O}\right.$, ReagentPlus $\left.{ }^{\circledR}, \geq 99.0 \%\right)$; sulfuric acid concentrate $\left(0.1 \mathrm{M} \mathrm{H}_{2} \mathrm{SO}_{4}\right.$ in water $\left.(0.2 \mathrm{~N})\right)$; chloroform (CHROMASOLV Plus, for HPLC, $\geq 99.9 \%$ ); methanol (CHROMASOLV, for HPLC, $\geq 99.9 \%$ ); ammonium sulfate $\left(\left(\mathrm{NH}_{4}\right)_{2} \mathrm{SO}_{4}\right.$, ReagentPlus, $\geq 99.0 \%$ ); sodium chloride ( $\mathrm{NaCl}$, BioXtra, $\geq 99.5 \%$ (AT)); iron(II) sulfate heptahydrate $\left(\mathrm{FeSO}_{4} \cdot 7 \mathrm{H}_{2} \mathrm{O}\right.$, BioReagent, $\geq 99 \%$ ); monopotassium phosphate $\left(\mathrm{KH}_{2} \mathrm{PO}_{4}, \geq 99 \%\right)$; dipotassium hydrogenphosphate $\left(\mathrm{K}_{2} \mathrm{HPO}_{4}, \geq 99 \%\right)$; sucrose (BioXtra, $\geq 99.5 \%$ ); select yeast extract; zinc sulfate heptahydrate ( $\mathrm{ZnSO}_{4} \cdot 7 \mathrm{H}_{2} \mathrm{O}$, BioReagent); manganese(II) sulfate tetrahydrate $\left(\mathrm{MnSO}_{4} \cdot 4 \mathrm{H}_{2} \mathrm{O}\right.$, BioReagent); Boric acid $\left(\mathrm{H}_{3} \mathrm{BO}_{3}\right.$, BioReagent, $\left.299.5 \%\right)$; Copper(II) sulfate pentahydrate $\left(\mathrm{CuSO}_{4} \cdot 5 \mathrm{H}_{2} \mathrm{O}\right.$, BioReagent, $\left.\geq 98 \%\right)$; sodium molybdate dihydrate $\left(\mathrm{Na}_{2} \mathrm{MoO}_{4} \cdot 2 \mathrm{H}_{2} \mathrm{O}\right.$, ACS reagent, $\geq 99 \%)$; cobalt(II) chloride hexahydrate $\left(\mathrm{CoCl}_{2} \cdot 6 \mathrm{H}_{2} \mathrm{O}\right.$, BioReagent); EDTA (ethylenediaminetetraacetic acid, ACS reagent $\geq 99 \%$ ); nickel(II) chloride hexahydrate $\left(\mathrm{NiCl}_{2} \cdot 6 \mathrm{H}_{2} \mathrm{O}\right.$, BioReagent); and potassium iodide (KI, BioXtra, $\geq 99.0 \%$ ), all of them were purchased from Sigma-Aldrich Canada Co., ON, Canada.

\subsection{Methods}

\subsection{1. nZVI-Aided PCB Dechlorination}

(1) PCB-Contaminated Soil Preparation. The synthesized soil that contaminated by transformer oil was applied to simulate PCB-contaminated oil spills such as uncontrolled waste disposals or leakage of storage tanks. The soil was dried at room temperature for one week and passed through a $2 \mathrm{~mm}$ stainless steel sieve to remove any coarse sand and gravel particles as well as to improve the homogeneity before use. Then soil characterization was conducted. After characterization, PCB-contaminated soil was prepared in two
$20 \mathrm{~L}$-stainless steel trays. Each tray was filled with $10 \mathrm{~kg}$ of soil and $2 \mathrm{~L}$ of transformer oil. The soil and oil were mixed thoroughly until it reached a homogenous phase. The trays were then covered with tin foil and stored for one week. After that, the oil in the tray was drained off until there was no fluid in soil, and the soil was ready for nZVI treatment.

(2) Air-Stable nZVI Powder Activation. Before any experiment, the surface character and crystal structure of these commercial nZVI particles were examined by scanning electron microscopy (SEM) and X-ray Diffraction (XRD), respectively, in the Core Research Equipment \& Instrument Training Lab (CREAIT) at Memorial University. For the activation, the air-stable nanopowder of nZVI was mixed with deionized water at a ratio of $1: 4$. The mixture was then activated by a Branson Sonifier ${ }^{\mathrm{TM}}$ S-450D digital ultrasonic homogenizer for 2 mins at $50 \%$ amplitude. The treated mixture was sealed and stored at room temperature for two days before dechlorination experiments.

(3) Dechlorination. Activated nZVI slurry was transferred into a $500 \mathrm{~mL}$ wide neck amber glass bottle with $200 \mathrm{~g}$ PCBcontaminated soil; and $30 \mathrm{~mL}$ deionized water was added as well. The solid and liquid phases were thoroughly mixed and each bottle was covered with a solid-top cap. The homogenous mixture was then stored at room temperature and let the reaction between nZVI particles and PCBs last for 75 days. The effects of the nZVI dosage $(5,7.5,10,12.5$, and $15 \mathrm{~g}$ per $\mathrm{kg}$ PCB-contaminated soil), initial $\mathrm{pH}(2,5)$, and temperatures $\left(0^{\circ} \mathrm{C}, 35^{\circ} \mathrm{C}\right.$, and $\left.100^{\circ} \mathrm{C}\right)$ were investigated, respectively.

\subsubsection{Biosurfactant-Aided Soil Washing}

(1) Batch-Scale Washing System Design and Setup. The experimental setup used to perform soil washing experiments consists of a washing fluid reservoir, a soil column, a peristaltic pump, and an effluent collection system (Figure 1). The peristaltic pump contains variable speed drives that can run from 0.4 to $85.0 \mathrm{~mL} / \mathrm{min}$. The soil column is made of glass to avoid any interference from phthalate esters when contacting with plastic materials, and with a cylindrically diameter of $19 \mathrm{~mm}$ and $15 \mathrm{~cm}$ in length. The column was packed with $25 \mathrm{~g}$ of nZVI-treated soil and the outlet end of the column was fitted with glass beads and glass wool to prevent soil loss during washing. The system assembly is shown in Figure 1.

(2) Biosurfactant Production and Washing Fluid Preparation. The bacteria used to generate biosurfactant were isolated from the Atlantic Ocean recently. Till now, no commercial biosurfactant products associated with this strain were available. Thus, biosurfactants need to be produced before conducting washing experiments. For the media and cultivation conditions, a medium modified from Peng et al. [29] was used, which contains the following composition (g/L): sucrose (10), $\mathrm{KH}_{2} \mathrm{PO}_{4}(3.4), \mathrm{K}_{2} \mathrm{HPO}_{4}(4.4),\left(\mathrm{NH}_{4}\right)_{2} \mathrm{SO}_{4}$ (10.0), $\mathrm{FeSO}_{4} \cdot 7 \mathrm{H}_{2} \mathrm{O}\left(2.8 \times 10^{-4}\right), \mathrm{NaCl}(2.2), \mathrm{MgSO}_{4} \cdot 7 \mathrm{H}_{2} \mathrm{O}$ (1.02), yeast extract (0.5), and $0.5 \mathrm{~mL}$ of trace element solution including $(\mathrm{g} / \mathrm{L}) \mathrm{ZnSO}_{4} \cdot 7 \mathrm{H}_{2} \mathrm{O}$ (2.32), $\mathrm{MnSO}_{4} \cdot 4 \mathrm{H}_{2} \mathrm{O}$ (1.78), 


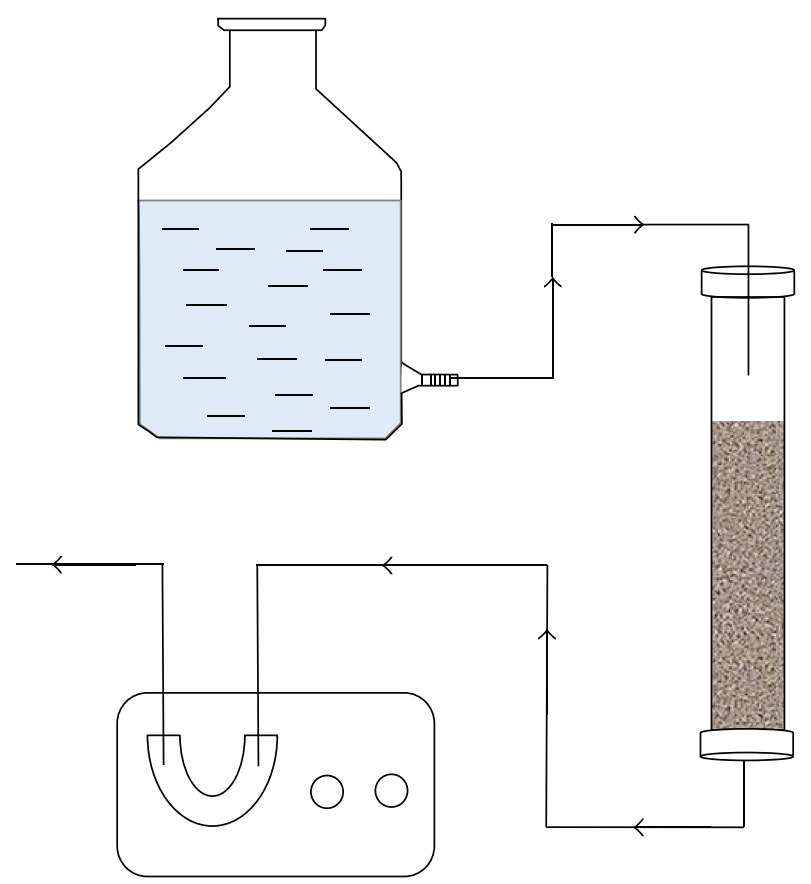

FIGURE 1: Sketch of soil washing system assembly.

$\mathrm{H}_{3} \mathrm{BO}_{3}$ (0.56), CuSO $4 \cdot 5 \mathrm{H}_{2} \mathrm{O}(1.0), \mathrm{Na}_{2} \mathrm{MoO}_{4} \cdot 2 \mathrm{H}_{2} \mathrm{O}(0.39)$, $\mathrm{CoCl}_{2} \cdot 6 \mathrm{H}_{2} \mathrm{O}(0.42)$, EDTA (1.0), $\mathrm{NiCl}_{2} \cdot 6 \mathrm{H}_{2} \mathrm{O}$ (0.004), and KI (0.66). Cultivations were performed in $1 \mathrm{~L}$ Erlenmeyer flasks containing $750 \mathrm{~mL}$ medium at $30^{\circ} \mathrm{C}$ and stirred in a rotary shaker for 7 days. Enriched culture medium after 7 days was centrifuged at $10,000 \mathrm{rpm}$ for $10 \mathrm{~min}$, and the supernatant layer was extracted using chloroform-methanol $(1: 2)$ on a magnetic stirrer for 8 hours. The solvent layer was separated from the aqueous phase and the solvent was removed by rotary evaporation at $40^{\circ} \mathrm{C}$ and $60 \mathrm{rpm}$ under reduced pressure. The CMC of the resulting crude biosurfactants was determined through measuring the surface tension in accordance with ASTM D1331-14 method. The surface tension of a crude biosurfactant solution was measured by using Du Noüy Tensiometer. The CMC value of the crude biosurfactants was estimated by the surface tension curve over a wide concentration range. They were determined by noting the concentrations at which the surface tension reaches the minimum.

(3) Soil Washing. Parallel experiments were conducted to investigate the effect of nanoiron particles on soil washing treatment. Both of the PCB-contaminated soil samples treated with $7.5 \mathrm{~g} / \mathrm{kg}$ and without nZVI particles were loaded into the washing columns, respectively, to test whether the presence of nanoparticles would have any effect on soil washing. Twenty-five grams of the soil was washed with deionized water in a down flow mode for 1.5 hours at a steady flow rate controlled by the peristaltic pump. To investigate the effect of crude biosurfactant, the soil samples were washed with the crude biosurfactant solution $(0.25 \%, 0.5 \%$, and $3 \% \mathrm{v} / \mathrm{v}$ ) in a down flow mode for 3 hours at a steady flow rate controlled by the peristaltic pump. The washing effluents were sampled at $0,10,20,30,60,90,120$, and 180 minutes of washing to investigate the change of $\mathrm{PCB}$ concentration with time. The change of PCB concentration in soil was determined by measuring the soil sample before and after washing.

2.2.3. Sample Analysis. The PCBs in each soil sample were first extracted into the solvent phase according to EPA method 3550B ultrasonic extraction. A modification of the method was conducted to achieve a better testing performance. Two grams of soil sample was transferred to a $30 \mathrm{~mL}$ beaker. Two grams of anhydrous sodium sulfate was added to the sample and the solution was well mixed. Two surrogates, $500 \mu \mathrm{L} 10$ ppm biphenyl- $\mathrm{d}_{10}$ and $200 \mu \mathrm{L} 10$ ppm EPA 525, 525.1 PCB Mix, were spiked to the sample. A hexane solvent of $9.3 \mathrm{~mL}$ was immediately added to the matrix in order to bring the final volume to $10.0 \mathrm{~mL}$. This was followed by disrupting the sample with a Branson Sonifier ultrasonic probe for 2 minutes at 50\% amplitude. After ultrasonic extraction, $1 \mathrm{~mL}$ extract was filtered by glass wool and ready for solid phase extraction (SPE) cleanup. Supelclean Sulfoxide SPE cartridges purchased from Sigma-Aldrich were used for transformer oil cleanup. The SPE normal procedure of conditioning, loading, washing, and elution was followed. The conditioning was accomplished by eluting $10 \mathrm{~mL}$ of acetone to remove residual moisture from the Supelclean Sulfoxide cartridges. This was followed by adding $20 \mathrm{~mL}$ of $\mathrm{n}$-hexane to equilibrate the cartridges. The pretreated $1 \mathrm{~mL}$ sample was loaded onto the cartridge and washed with $5.5 \mathrm{~mL}$ of n-hexane. Elution was done with $13 \mathrm{~mL}$ of $\mathrm{n}$-hexane. The eluate was concentrated to $1 \mathrm{~mL}$ by gentle air blow. The cleanup extracts were transferred into GC vials ready for analysis.

The PCB concentration in liquid phase was analyzed using modified Liquid-Liquid Microextraction (LLME) [30] followed by the GC-MS analysis. For modified LLME, $25 \mu \mathrm{L}$ of 10 ppm biphenyl- $\mathrm{d}_{10}$ and $10 \mu \mathrm{L}$ of 10 ppm EPA $525,525.1$ PCB Mix were spiked as surrogates to each $10 \mathrm{~mL}$ water sample (25 ng/L biphenyl- $\mathrm{d}_{10}$ and $10 \mathrm{ng} / \mathrm{L}$ EPA 525, 525.1 PCB Mix aqueous solution), which was treated by vortex mixing for $10 \mathrm{sec}$. This was followed by adding $500 \mu \mathrm{L}$ of hexane and the vortex mixing for $1 \mathrm{~min}$. The water sample was then centrifuged at 4,000 rpm for $5 \mathrm{~min}$. Ten $\mu \mathrm{L}$ of extract was transferred to Microvials for GC analysis. Instrumental analysis was performed using an Agilent 7890A/5975C gas chromatograph-mass spectrometer (GC-MS) equipped with an Agilent 7693 autosampler. GC conditions were set up based on EPA method 8082A. A few adjustments were made to ensure that no PCB congener was retained in the column.

Total ion current (TIC) chromatogram was acquired to examine the changes of PCBs in soil samples. The analysis of each congener and its surrogate was carried out in selected-ion monitoring (SIM) chromatogram. The ratio of sample congener response to standard congener response was defined as the relative concentration, which was used in the results and discussion. All the samples were treated and analyzed in duplicate. 
TABLE 1: Soil properties.

\begin{tabular}{lc}
\hline Properties & Results \\
\hline Soil pH & 7.53 \\
Bulk density & $1.78 \mathrm{~g} / \mathrm{cm}^{3}$ \\
Particle density & $2.71 \mathrm{~g} / \mathrm{cm}^{3}$ \\
Pore space & $34.3 \%$ \\
Moisture content & $0.069 \%$ \\
Cation exchange capacity & $95.22 \mathrm{cmol} / \mathrm{kg}$ \\
Hydraulic conductivity & $0.024 \mathrm{~cm} / \mathrm{s}$ \\
\hline
\end{tabular}

TABLE 2: Soil particle size distribution determined by sieve analysis.

\begin{tabular}{lcc}
\hline Particle & Diameter $(\mathrm{mm})$ & Size distribution $(\%)$ \\
\hline Gravel & $>2.0$ & 4.5 \\
Sand & $0.05-2.0$ & 92.5 \\
Silt & $0.002-0.05$ & 2.5 \\
Clay & $<0.002$ & 0.5 \\
\hline
\end{tabular}

\section{Results and Discussion}

\section{1. nZVI-Aided PCB Dechlorination}

3.1.1. Soil Characterization. Before the nZVI-aided PCB dechlorination experiments, basic soil properties including particle size distribution, soil $\mathrm{pH}$, bulk density, particle density, pore space, cation exchange capacity, hydraulic conductivity, and moisture content of the purchased plain soil were measured. The results are shown in Tables 1 and 2 . The plain soil used in this research was mainly composed of sand, which was suitable for soil washing. The bulk density, particle density, pore space, hydraulic conductivity, and moisture content are physical properties which can be greatly influenced by soil composition and particle size distribution. The $\mathrm{pH}$ of the soil was slight alkalinity, which could result in a higher cation exchange capacity (CEC) value. In an environmental context, CEC stands for the ability of soil to adsorb contaminants. The $\mathrm{pH}$ and CEC are two important chemical properties which could affect the soil remediation process and thus need to be examined before remediation.

Metal substances of the plain soil sample were characterized by ICP-MS. Table 3 displays the analytical results. It is noticed that a high concentration of iron was present, which was of $33.6 \mathrm{~g}$ per $\mathrm{kg}$ soil. The addition of $\mathrm{nZVI}$ for PCB dechlorination thus would not much influence the composition of soil.

3.1.2. Analysis of PCB Concentrations in the Original Spiked Soil. The concentrations of PCBs in the spiked soil sample were evaluated before conducting the dechlorination and soil washing experiments. Four PCB congeners were selected as analytes due to their high abundances in the transformer oil, namely Penta-17.8, Penta-18.7, Penta-20.0, and Hexa-20.8. The former parts of the names represent the numbers of chlorine atoms in the congener compounds, while the latter ones are their corresponding retention times (minutes) in the
TABLE 3: Metal substances in the soil sample determined by ICP-MS.

\begin{tabular}{lc}
\hline Metals & Concentration in soil $(\mathrm{mg} / \mathrm{kg})$ \\
\hline Arsenic & 5.306 \\
Barium & 643.918 \\
Cadmium & 0.146 \\
Chromium & 16.815 \\
Copper & 13.727 \\
Iron & $33,562.114$ \\
Lead & 17.681 \\
Mercury & $<\mathrm{LDL}$ \\
Nickel & 9.142 \\
Selenium & $<\mathrm{LDL}$ \\
Thallium & 0.444 \\
Uranium & 1.675 \\
Vanadium & 46.084 \\
Zinc & 71.958
\end{tabular}

Note: $\mathrm{LDL}=$ lower detection limit.

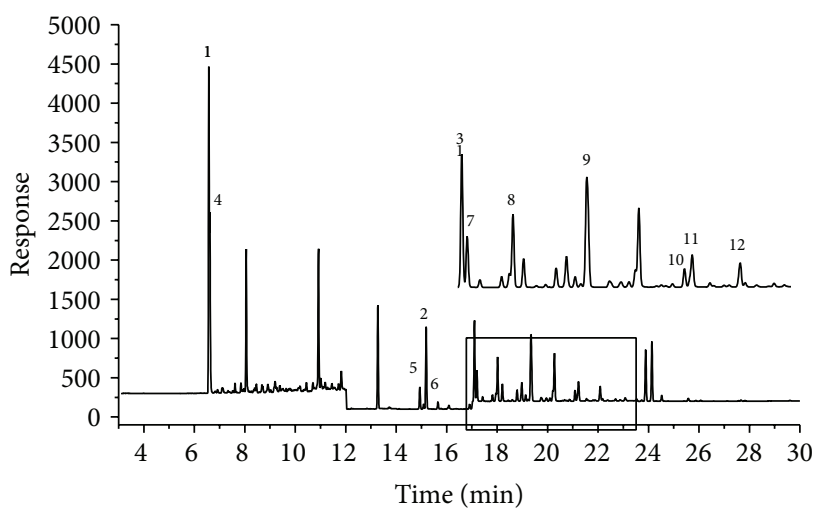

FIgURE 2: GC-MS SIM spectra of PCBs in contaminated soil sample spiked with bipenyl- $\mathrm{d}_{10}$ and EPA 525,525.1 PCBs standard. (1) Biphenyl- $d_{10}$. (2) 2,2',4,4' -Tetrachlorobiphenyl. (3) $2,2^{\prime}, 3^{\prime}, 4,6$ Pentachlorobiphenyl. (4) Biphenyl. (5) Tetra-15.6. (6) Tetra-16.3. (7) Penta-17.8. (8) Penta-18.7. (9) Penta-20.0. (10) Hexa-20.8. (11) Hexa21.8. (12) Hexa-22.8.

TABLE 4: The initial relative concentrations of PCBs in the spiked soil.

\begin{tabular}{lcc}
\hline Analytes & Surrogate & Response ratio \\
\hline Penta-17.8 & $2,2^{\prime}, 3^{\prime}, 4,6$-Pentachlorobiphenyl & 0.384 \\
Penta-18.7 & $2,2^{\prime}, 3^{\prime}, 4,6$-Pentachlorobiphenyl & 0.551 \\
Penta-20.0 & $2,2^{\prime}, 3^{\prime}, 4,6$-Pentachlorobiphenyl & 0.736 \\
Hexa-20.8 & $2,2^{\prime}, 3^{\prime}, 4,6$-Pentachlorobiphenyl & 0.262 \\
\hline
\end{tabular}

MS spectra (Figure 2). The average response ratios of PCBs to their corresponding surrogates are listed in Table 4.

3.1.3. nZVI Characterization and Activation. The commercial nZVI particles were characterized by SEM and XRD prior to their applications in PCB dechlorination in soil. Figure 3 shows the SEM image of nZVI particles. It can be seen that 


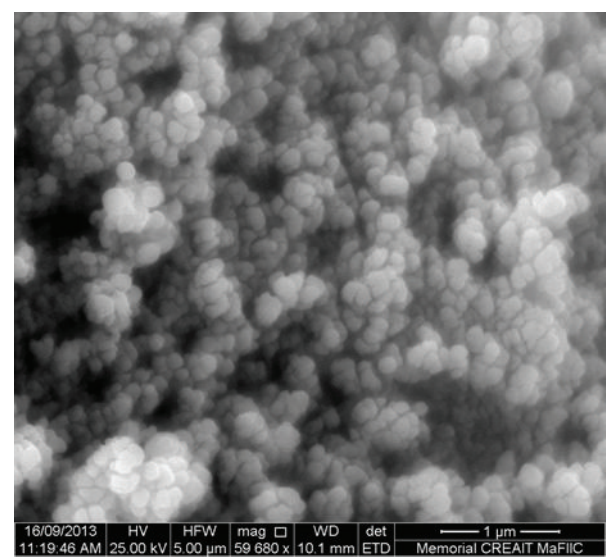

FIGURE 3: SEM Image of the commercial nZVI particles.

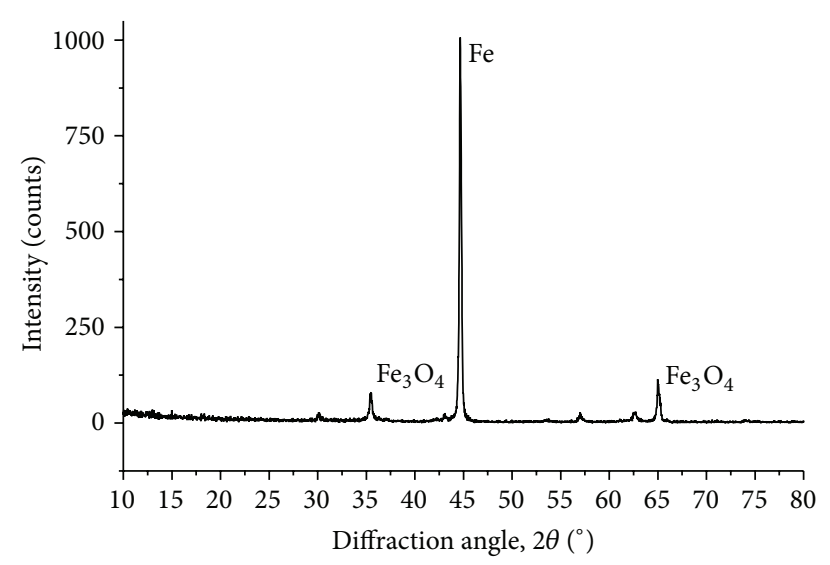

FIGURE 4: XRD of the nZVI particle.

the majority of the particles were nearly spherical in shape and uniform in size. The particle size was in the range of $20-$ $100 \mathrm{~nm}$ with an average particle size of $50 \mathrm{~nm}$.

Figure 4 displays the XRD pattern of the nZVI particles and it proved that there were crystal iron particles existed in the commercial product. The $2 \theta$ values of the peaks were compared with the standard data for iron and its oxides such as magnetite and $\alpha$-Fe. Apparent peak at the $2 \theta$ of $44.9^{\circ}$ indicates the presence of $\alpha$-Fe, while other apparent peaks show the presence of iron oxides. The redox potential of nZVI slurry was decreased from $360 \mathrm{mV}$ to $-300 \mathrm{mV}$ after the activation.

3.1.4. Natural Attenuation of PCBs. The changes of РСB concentrations in the contaminated soil were tracked on the 1 st, 15th, and 45th day, respectively, during the natural attenuation process. As depicted in Figure 5, the concentrations of all the four congeners did not change significantly within the 45-day period. It illustrated that the dechlorination rates of PCBs during the natural attenuation process were extremely slow. It also proved that the PCBs were not able to be degraded without any additional treatment.

3.1.5. Effect of $n Z V I$ Dosage. The performance of PCB dechlorination using different nZVI dosages is shown in Figure 6.

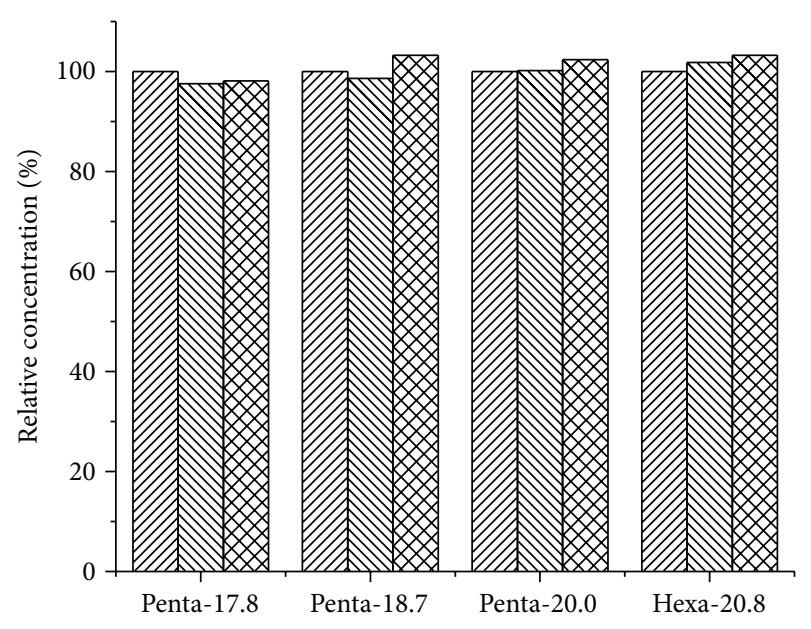

VIIA Day 1

Day 15

Day 45

Figure 5: Natural attenuation of PCBs in contaminated soil.

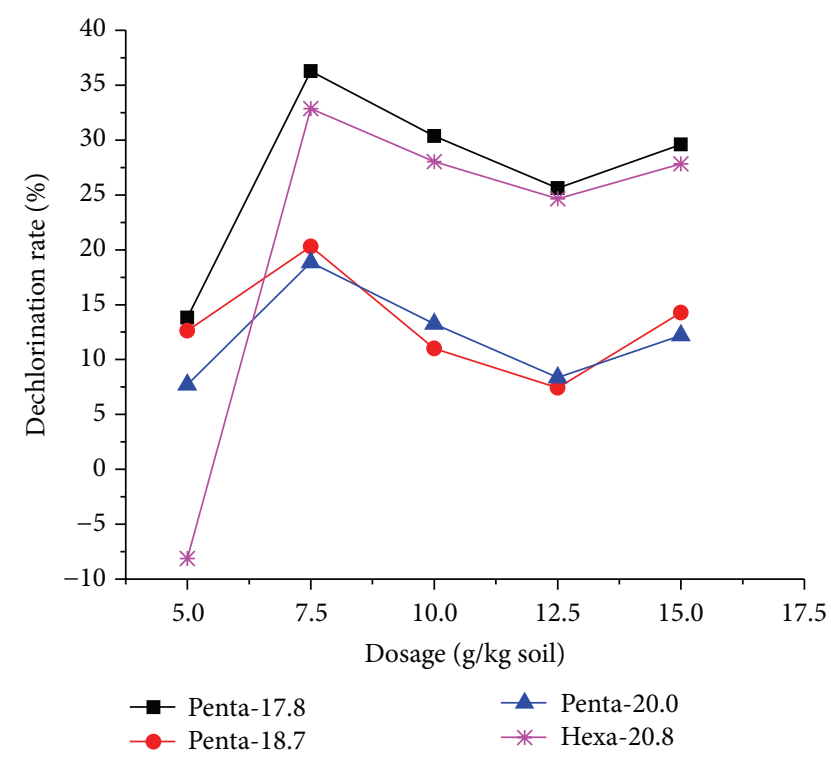

FIgURE 6: Effect of nZVI dosage on PCB dechlorination in the contaminated soil.

The trends of the PCB dechlorination rate versus nZVI dosage were similar based on the results of all the four congeners. The overall PCB dechlorination rate was first increased as nZVI dosage increased from 5 to $7.5 \mathrm{~g} / \mathrm{kg}$, indicating that the increase of nZVI dosage can accelerate the dechlorination of PCBs. The overall dechlorination rate of PCBs was then decreased when the nZVI dosage increased higher than $7.5 \mathrm{~g} / \mathrm{kg}$. The maximum dechlorination rates of Penta-17.8, Penta-18.7, Penta-20.0, and Hexa-20.8 during 75 days period were $36.3 \%, 20.3 \%, 18.9 \%$, and $32.9 \%$, respectively. The results indicated that when choosing $7.5 \mathrm{~g} / \mathrm{kg}$ as the nZVI dosage, the highest dechlorination rates were achieved in all four congeners. Adding more nZVI particles had shown a negative 


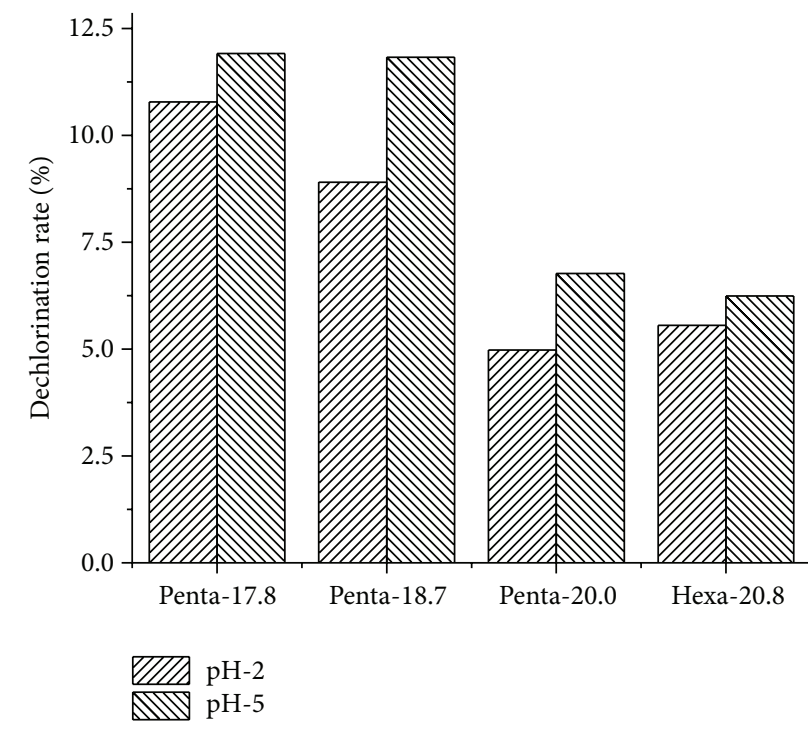

Figure 7: Effect of $\mathrm{pH}$ on PCB dechlorination in the contaminated soil.

influence on PCB dechlorination. This was possibly due to the particle aggregation formed during mixing [31]. Besides the nZVI aggregation, the biotransformation from higher chlorinated biphenyls to lower ones may also affect the PCB dechlorination rate under multiple nZVI dosages. Based on the experimental results, the $\mathrm{nZVI}$ dosage of $7.5 \mathrm{~g} / \mathrm{kg}$ with the best PCB dechlorination performance was selected for the following treatments.

3.1.6. Effect of $\mathrm{pH}$ Level. Two levels of $\mathrm{pH}$ were selected to evaluate the effect of $\mathrm{pH}$ on $\mathrm{PCB}$ dechlorination. The result is shown in Figure 7. After 75 days monitoring, the average dechlorination rates of Penta-17.8, Penta-18.7, Penta20.0 , and Hexa-20.8 at $\mathrm{pH}$ of 2 were $10.8 \%, 8.9 \%, 5.0 \%$, and $5.6 \%$, respectively; while their average dechlorination rates at $\mathrm{pH}$ of 5 were $11.9 \%, 11.8 \%, 6.8 \%$, and $6.2 \%$, respectively. The dechlorination rates of each PCB congener were higher at $\mathrm{pH}$ of 5 than those at $\mathrm{pH}$ of 2 . Previous studies have shown that an acid environment with more protons could accelerate the PCB dechlorination [32]. The results of this study led to a different conclusion. It might be because, in this case, the protons were sufficient at $\mathrm{pH}$ of 5 so that $\mathrm{pH}$ was not a dominating factor on PCB dechlorination anymore. In addition, the addition of $\mathrm{H}_{2} \mathrm{SO}_{4}$ would have more interference with the mass transfer of $\mathrm{PCBs}$ from the soil to the iron $(\mathrm{Fe})$ surface [32]. The $\mathrm{pH}$ of 5 was thus selected to be the initial $\mathrm{pH}$ condition in the following experiments.

3.1.7. Effect of Temperature. The effect of temperature on PCB dechlorination after 75 days was investigated with results shown in Figure 8. The PCB dechlorination was greatly enhanced when the temperature increased from 0 to $100^{\circ} \mathrm{C}$. As the temperature increased, the $\mathrm{PCB}$ dechlorination of Penta-17.8 improved the most, with a rate change from $10.1 \%$ to $34.2 \%$. The dechlorination rates of Penta-18.7, Penta-20.0, and Hexa-20.8 were enhanced from $11.3 \%$ to $32.2 \%$, from

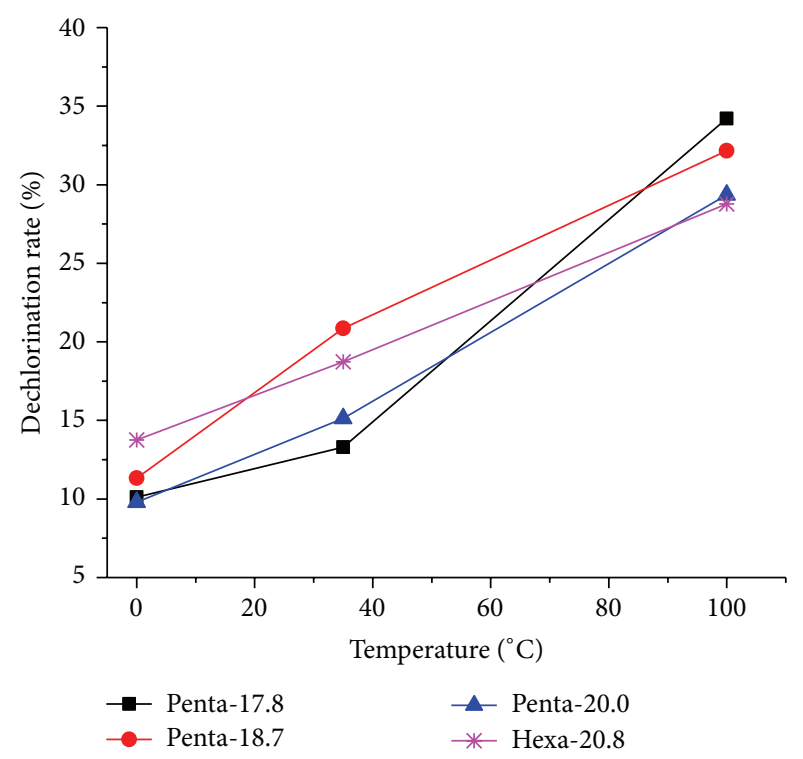

FIGURE 8: Effect of temperature on nZVI-aided PCB dechlorination.

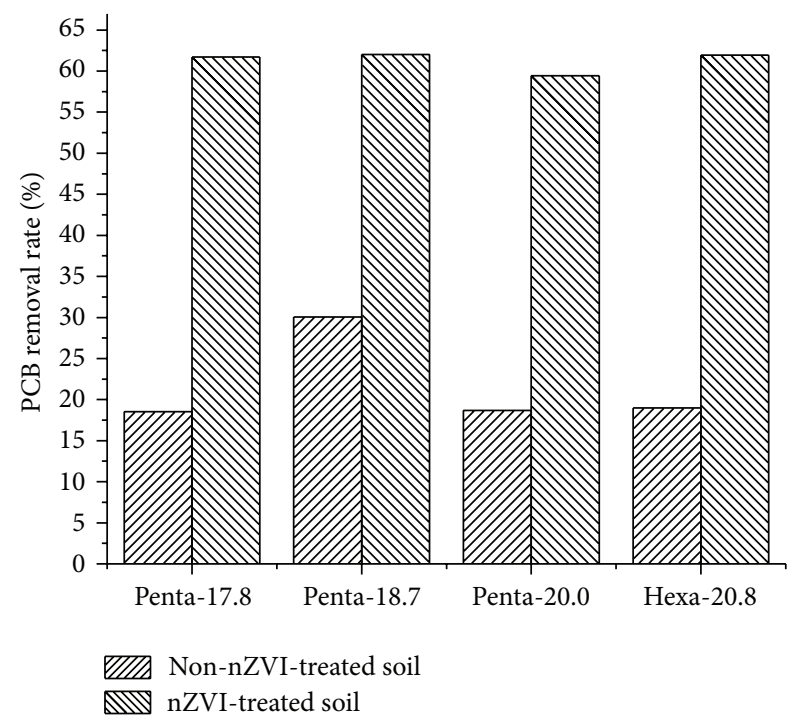

FIGURE 9: Effect of the nZVI particles on PCB removal during soil washing.

$9.8 \%$ to $29.4 \%$, and from $13.7 \%$ to $28.8 \%$, respectively. These results showed that a temperature increase would enhance the mobility of PCBs from the soil to the iron surfaces and thus accelerate the dechlorination reaction [32].

\subsection{Biosurfactant-Aided Soil Washing}

3.2.1. Effect of nZVI Particles on Soil Washing. The effect of the nZVI particles on PCB removal during the soil washing treatment was investigated. Figure 9 showed the results. Although the insolubility of PCBs makes their distribution negligible in water phase, the PCBs in the transformer oil could be flushed out of the column due to the high flow rate during direct soil washing without using any biosurfactants. 


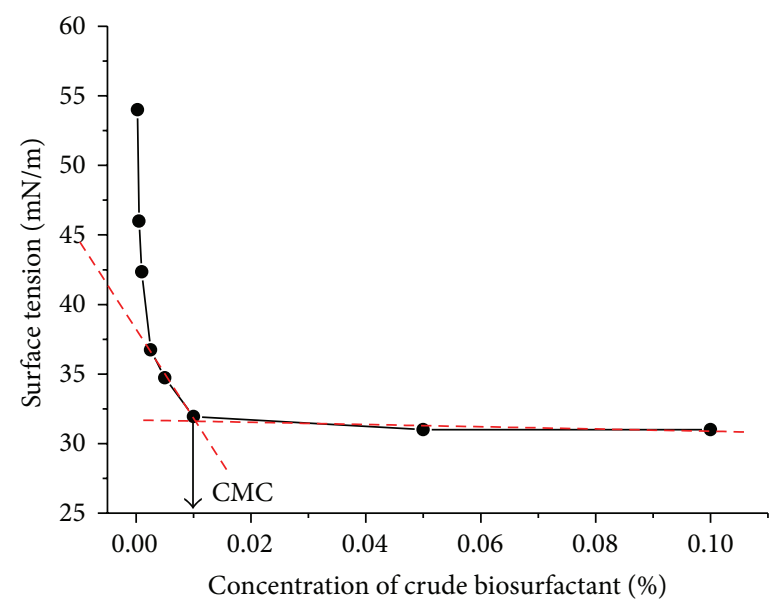

FIGURE 10: CMC of the crude biosurfactant.

As shown in Figure 9, after 1.5 hours of operation, about 18\% to $30 \%$ of PCBs in the congeners were removed by direct washing of the non-nZVI-treated soil.

After the nZVI-aided dechlorination, a red color was observed in the treated soil, implying the formation of ferric hydroxides or ferric oxides. It indicated that the nZVI particles were transferred to their oxidative forms after the reaction. During washing of the nZVI-treated soil, the PCB concentration of each congener was significantly decreased. In Figure 9, the removal rates of PCBs after washing were between $60 \%$ and $62 \%$ in the nZVI-treated soil. It was illustrated that the treatment by the nZVI particles greatly enhanced the soil washing efficiency. Besides, the presence of nanoscale ferric oxides in the system plays a key role in PCB removal [33]. The contaminated soil trapped a certain amount of transformer oil, and the oil droplets were blocked by the pore throat of soil due to the high interfacial tension between oil and soil [34]. With the presence of nanoscale ferric oxides, the interfacial tension would be reduced and the mobility of oil droplets would be increased [33]. As a result, more oil droplets were desorbed from the soil, resulting in an increased effectiveness of soil washing. This experiment confirmed that the combination of the nZVI-aided dechlorination and soil washing is reasonable and feasible.

3.2.2. CMC of the Crude Biosurfactant. The surface tension of a series of biosurfactant solutions with different biosurfactant concentrations was tracked. The trend of surface tension versus biosurfactant concentration was shown in Figure 10. The value of surface tension was decreased sharply till the biosurfactant concentration reached $0.01 \%$. When the biosurfactant concentration was higher than $0.01 \%$, the surface tension changes became relatively stable. Therefore, the CMC of the crude biosurfactant was determined to be $0.01 \%$.

\subsubsection{Effect of Biosurfactant Concentration on Soil Washing.} The nZVI-treated soil sample was washed by crude biosurfacant solutions. The concentration of crude biosurfactant in the washing fluid was set as $3 \%, 0.5 \%$, and $0.25 \%$. The initial flow rate of the column washing fluid was set within the range of $18-20 \mathrm{~mL} / \mathrm{min}$. The results of relative $\mathrm{PCB}$ concentrations (the ratio of sample congener response to standard congener response) in column effluent were shown in Figures 11(a)-11(c). The elution of PCBs started at $10 \mathrm{~min}$. The PCB concentrations in effluents were sharply increased and reached their peaks at $15-45 \mathrm{~min}$. Steep declines were followed by the peaks and the gentle deduction appeared in the final stage.

The overall PCB removal rates after washing of the nZVItreated soil were examined. As shown in Figure 12, the higher the concentration of the crude biosurfactant solution used, the higher the removal rate achieved. The maximum removal rate was found when using 3\% crude biosurfactant and $90 \%$ of the total four PCB congeners were removed from the soil. The final removal rates using $0.5 \%$ and $0.25 \%$ crude biosurfactant solutions were $80 \%$ and $75 \%$, respectively. The PCB removal rates using all the three crude biosurfactant solution were higher than $75 \%$, indicating the promising effectiveness of biosurfactant-aided soil washing.

The decreasing of washing flow rates occurred especially with higher biosurfactant doses. When supplying the washing fluid with the $3 \%$ crude biosurfactant, a backwashing step was required within 30-60 min washing time. It was observed that the bounce of PCBs at 60 min in Figure 11(a) was because of backwash. The most possible explanation is that the crude biosurfactant contained insoluble particulate matter could block the pathway of washing flow, thus reducing both flow rate and emulsification rate. It could further lead to a longer treatment period. Results indicated that the crude biosurfactant solution with a concentration of $0.5 \%$ could remove the majority of the four PCB congeners with the shortest treatment time (within 60 minutes). Therefore, $0.5 \%$ was selected as an appropriate biosurfactant concentration for further applications.

The SIM spectrum shows the removal of almost all the PCBs in the soil sample after washing. As shown in Figure 13, the peaks of PCBs had almost disappeared after washing with $0.5 \%$ crude biosurfactant solution; only the peaks of surrogates were left. Besides, the contents of the transformer oil that generated the baseline wander were also removed. As a consequence, the crude biosurfactant solution was able to remove almost all the organic components including PCBs in transformer oil unselectively.

\section{Conclusions}

This research has focused on the development of a twostep treatment consisting of nZVI-aided dechlorination followed by biosurfactant-based soil washing technology to remove $\mathrm{PCBs}$ from soil. In nZVI-aided dechlorination, the effects of nZVI dosage, initial $\mathrm{pH}$, and temperature on $\mathrm{PCB}$ transformation were evaluated one at a time, respectively. The selected dosage of nZVI was $7.5 \mathrm{~g} / \mathrm{kg}$ soil. Adding more nZVI particles could have negative influence on PCB dechlorination, since the aggregates could be easily formed as the nZVI dosage increases. An environment with $\mathrm{pH}$ lower than 5 did not much influence the removal rates of PCBs, indicating the presence of sufficient protons in the system. The results showed that the lower $\mathrm{pH}$ would actually inhibit 


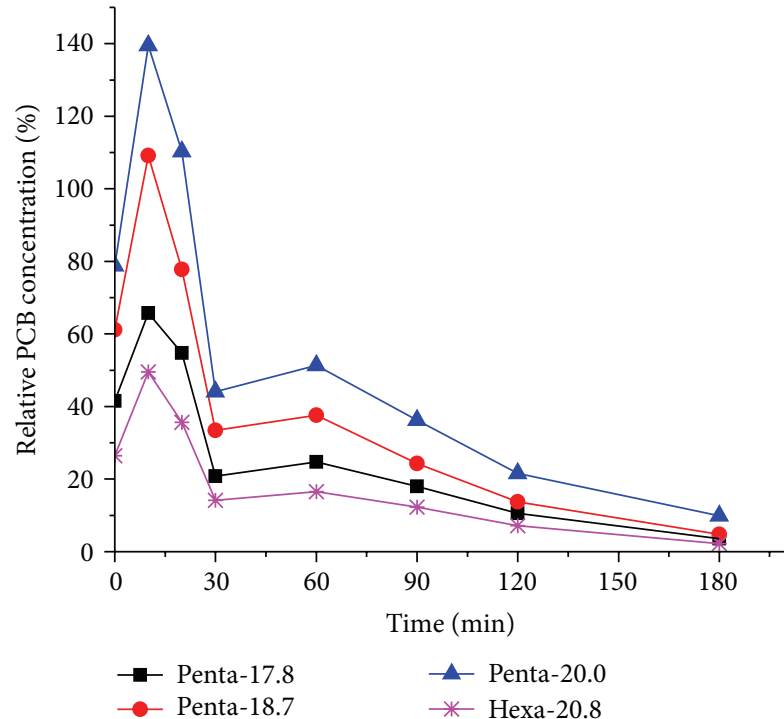

(a)

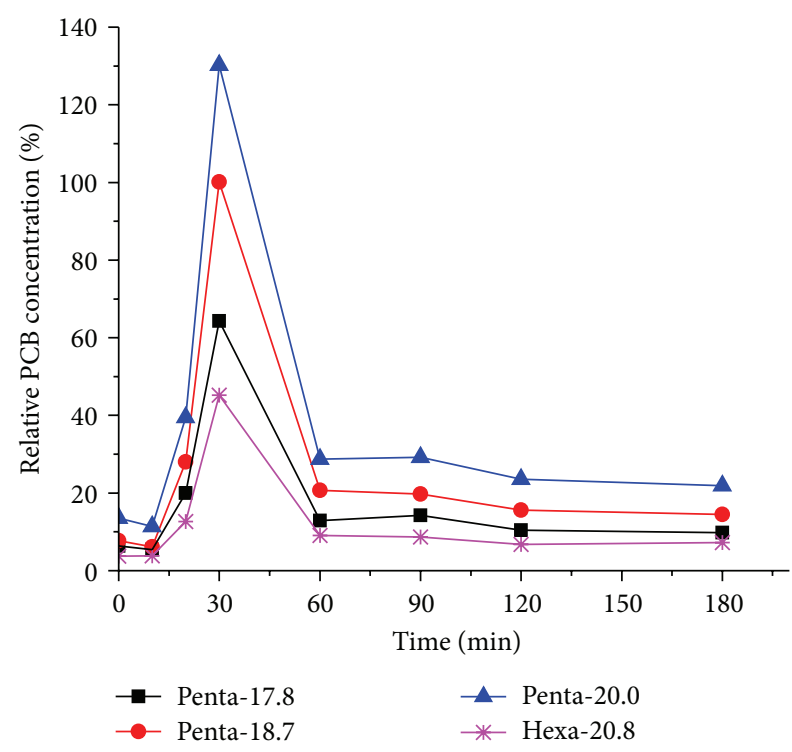

(b)

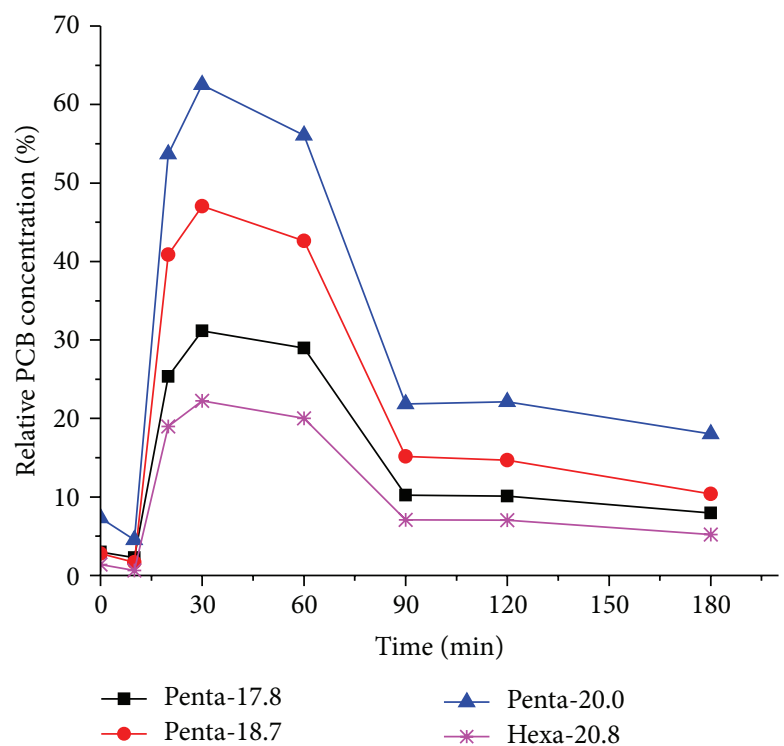

(c)

FIGURE 11: Relative concentrations of PCBs in washing effluent with (a) $3 \%$, (b) $0.5 \%$, and (c) $0.25 \%$ crude biosurfactant solution.

the dechlorination by the presence of $\mathrm{H}_{2} \mathrm{SO}_{4}$, which has an effect on the reduction of mass transfer. An improvement of dechlorination was observed as the temperature increased, since higher temperature would accelerate the dechlorination reaction.

In the soil washing system, the presence of nZVI particles plays a key role in PCB removal. They can greatly enhance the soil washing efficiency because the interfacial tension between the oil phase and the soil phase would be reduced and the mobility of oil droplets would be increased. Soil washing of nZVI remediated soil can be enhanced by biosurfactant. Higher biosurfactant concentration could increase the solubilization of PCBs from soil phase to liquid phase. The overall PCB removal rates using all the three crude biosurfactant concentrations (3\%, $0.5 \%$, and $0.25 \%$ ) were $90 \%, 80 \%$, and $75 \%$, respectively, indicating the promising effectiveness of this biosurfactant. Compared with the $3 \%$ biosurfactant solution, the crude biosurfactant concentrations of $0.5 \%$ and $0.25 \%$ were more cost-effective. The $0.5 \%$ crude biosurfactant solution could remove the majority of PCBs within a shorter time than the solution with a concentration of $0.25 \%$. Therefore, $0.5 \%$ was recommended as an appropriate biosurfactant concentration for future application. This study shows a great potential in developing a promising treatment technology for PCB-contaminated soil remediation. Pilot-scale applications will be carried out to demonstrate the technology transfer.

\section{Competing Interests}

The authors declare that they have no competing interests. 


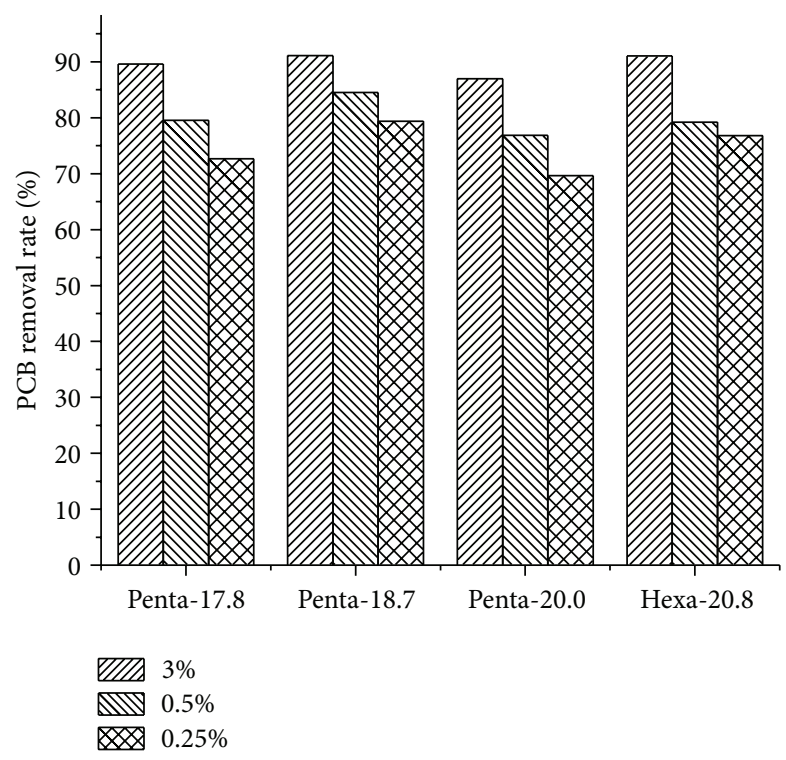

FIGURE 12: The washing efficiencies of PCBs in the nZVI-treated contaminated soil by different concentrations of crude biosurfactant solution.
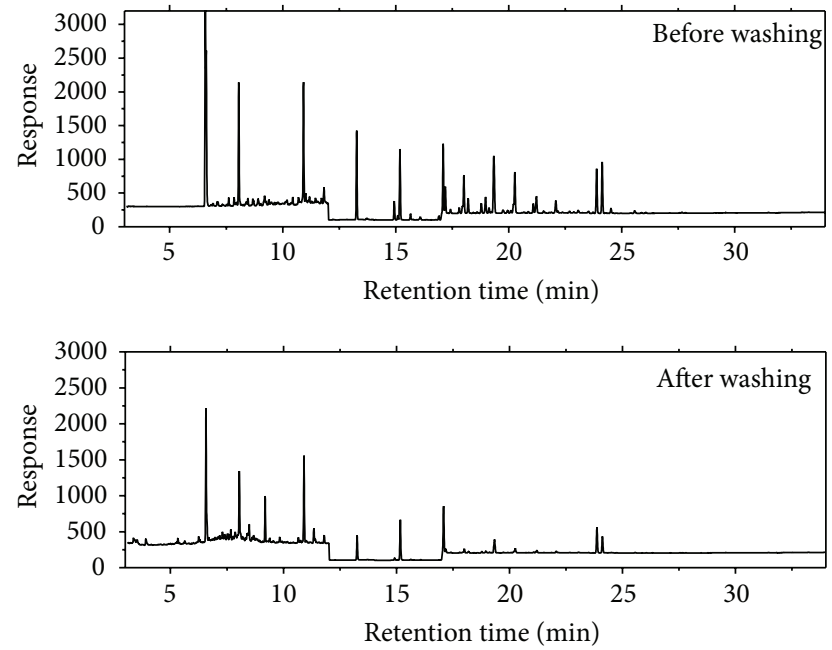

FIgURE 13: GC-MS SIM spectra of PCBs in the contaminated soil before and after washing by $0.5 \%$ crude biosurfactant solution.

\section{Acknowledgments}

The authors would like to express gratitude to The Natural Sciences and Engineering Research Council of Canada (NSERC) and the Canada Foundation for Innovation (CFI) for their support.

\section{References}

[1] D. Pal, J. B. Weber, and M. R. Overcash, "Fate of polychlorinated biphenyls (PCBs) in soil-plant systems," in Residue Reviews, pp. 45-98, Springer, New York, NY, USA, 1980.

[2] Canadian Council of Resource and Environment Ministers (CCREM), The PCB Story, (CCREM), Toronto, Canada, 1986.
[3] S. Tanabe, "PCB problems in the future: foresight from current knowledge," Environmental Pollution, vol. 50, no. 1, pp. 5-28, 1988.

[4] Canadian Council of Ministers of the Environment (CCME), "Canadian soil quality guidelines for the protection of environmental and human health: polychlorinated biphenyls (total)," in Canadian Environmental Quality Guidelines, Canadian Council of Ministers of the Environment, Winnipeg, Canada, 1999.

[5] US Environmental Protection Agency, PCBs in the United States industrial use and environmental distribution, p. 24, 1976, http://nepis.epa.gov/Exe/ZyPDF.cgi/2000I275.PDF?Dockey= 2000I275.PDF.

[6] S. Jensen, "Report of a new chemical hazard," New Scientist, vol. 32, no. 612, p. 445, 1966.

[7] W. M. J. Strachan, "Polychlorinated biphenyls (PCBs): fate and effects in the Canadian environment," EPS Report 4/HA/2, Environment Canada, 1988.

[8] L. A. Barrie, D. Gregor, B. Hargrave et al., "Arctic contaminants: sources, occurrence and pathways," Science of The Total Environment, vol. 122, no. 1-2, pp. 1-74, 1992.

[9] AMEC Earth and Environmental Ltd, Commission 88.1 Environmental Site Investigation B371 CHPP Tanks, Prepared for Defence Construction Canada, Goose Bay, Canada, 2008.

[10] Federal Contaminated Sites Portal, Federal Contaminated Sites Action Plan (FCSAP), February 2014, http://www.federalcontaminatedsites.gc.ca/default.asp?lang=en.

[11] A. Mikszewski, Emerging Technologies for the in Situe Remediation of PCB-contaminated Soils and Sediments: Bioremediation and Nanoscale Zerovalent Iron, US Environmental Protection Agency, 2004.

[12] S. M. Cook, Assessing the Use and Application of Zero-Valent Iron Nanoparticle Technology for Remediation at Contaminated Sites, Jackson State University, 2009.

[13] W.-X. Zhang, "Nanoscale iron particles for environmental remediation: an overview," Journal of Nanoparticle Research, vol. 5, no. 3-4, pp. 323-332, 2003.

[14] N. C. Mueller and B. Nowack, "Nanoparticles for remediation: solving big problems with little particles," Elements, vol. 6, no. 6, pp. 395-400, 2010.

[15] R. Varma, "Greener synthesis of noble metal nanostructures and nanocomposites," in Presented at the U.S. EPA Science Forum: Innovative Technologies-Key to Environmental and Economic Progress, Washington, DC, USA, 2008.

[16] W. Chu and K. H. Chan, "The mechanism of the surfactantaided soil washing system for hydrophobic and partial hydrophobic organics," Science of The Total Environment, vol. 307, no. 1-3, pp. 83-92, 2003.

[17] K. Urum, T. Pekdemir, and M. Gopur, "Optimum conditions for washing of crude oil-contaminated soil with biosurfactant solutions," Process Safety and Environmental Protection, vol. 81, no. 3, pp. 203-209, 2003.

[18] D. Feng, L. Lorenzen, C. Aldrich, and P. W. Maré, "Ex situ diesel contaminated soil washing with mechanical methods," Minerals Engineering, vol. 14, no. 9, pp. 1093-1100, 2001.

[19] H. I. Gomes, C. Dias-Ferreira, L. M. Ottosen, and A. B. Ribeiro, "Electrodialytic remediation of polychlorinated biphenyls contaminated soil with iron nanoparticles and two different surfactants," Journal of Colloid and Interface Science, vol. 433, pp. 189-195, 2014.

[20] T. Lyons, D. W. Grosse, and R. A. Parker, EPA engineering issue: technology alternatives for the remediation of $\mathrm{PCB}$ 
contaminated soils and sediments (No. EPA/600/S-13/079), Washington, DC, USA, 2013.

[21] B. Zhang, G. H. Huang, and B. Chen, "Enhanced bioremediation of petroleum contaminated soils through cold-adapted bacteria," Petroleum Science and Technology, vol. 26, no. 7-8, pp. 955-971, 2008.

[22] X. Qin, B. Chen, G. Huang, and B. Zhang, "A relation-analysisbased approach for assessing risks of petroleum-contaminated sites in Western Canada," New Developments in Sustainable Petroleum Engineering, vol. 1, no. 2, pp. 183-200, 2009.

[23] P. F. Amaral, M. A. Z. Coelho, I. M. Marrucho, and J. A. Coutinho, "Biosurfactants from yeasts: characteristics, production and application," in Biosurfactants, pp. 236-249, Springer, New York, NY, USA, 2010.

[24] H. Xia and Z. Yan, "Effects of biosurfactant on the remediation of contaminated soils," in Proceedings of the 4th International Conference on Bioinformatics and Biomedical Engineering (iCBBE '10), pp. 1-4, IEEE, Chengdu, China, June 2010.

[25] Unified Facilities Guide Specifications (USGS), Soil Washing through Separation/Solubilization, UFGS-02 54 23, 2010, https:// www.wbdg.org/ccb/DOD/UFGS/UFGS\%2002\%2054\%2023.pdf.

[26] H. I. Gomes, C. Dias-Ferreira, and A. B. Ribeiro, "Overview of in situ and ex situ remediation technologies for PCBcontaminated soils and sediments and obstacles for full-scale application," Science of the Total Environment, vol. 445-446, pp. 237-260, 2013.

[27] W. Y. Shiu and D. Mackay, "A critical review of aqueous solubilities, vapor pressures, Henry's law constants, and octanol-water partition coefficients of the polychlorinated biphenyls," Journal of Physical and Chemical Reference Data, vol. 15, no. 2, pp. 911929, 1986.

[28] Q. Cai, B. Zhang, B. Chen, Z. Zhu, W. Lin, and T. Cao, "Screening of biosurfactant producers from petroleum hydrocarbon contaminated sources in cold marine environments," Marine Pollution Bulletin, vol. 86, no. 1-2, pp. 402-410, 2014.

[29] F. Peng, Z. Liu, L. Wang, and Z. Shao, "An oil-degrading bacterium: Rhodococcus erythropolis strain 3C-9 and its biosurfactants," Journal of Applied Microbiology, vol. 102, no. 6, pp. 1603-1611, 2007.

[30] J. S. Zheng, B. Liu, J. Ping, B. Chen, H. J. Wu, and B. Y. Zhang, "Vortex- and shaker-assisted liquid-liquid microextraction (VSA-LLME) coupled with gas chromatography and mass spectrometry (GC-MS) for analysis of 16 polycyclic aromatic hydrocarbons (PAHs) in offshore produced water," Water, Air, and Soil Pollution, vol. 226, no. 9, pp. 318-331, 2015.

[31] N. C. Müller and B. Nowack, "Nano zero valent iron-the solution for water and soil remediation," Report of the Observatory NANO, 2010.

[32] P. Varanasi, A. Fullana, and S. Sidhu, "Remediation of PCB contaminated soils using iron nano-particles," Chemosphere, vol. 66, no. 6, pp. 1031-1038, 2007.

[33] L. Hendraningrat and O. Torsæter, "Metal oxide-based nanoparticles: revealing their potential to enhance oil recovery in different wettability systems," Applied Nanoscience, vol. 5, no. 2, pp. 181-199, 2015.

[34] A. Roustaei, S. Saffarzadeh, and M. Mohammadi, "An evaluation of modified silica nanoparticles' efficiency in enhancing oil recovery of light and intermediate oil reservoirs," Egyptian Journal of Petroleum, vol. 22, no. 3, pp. 427-433, 2013. 

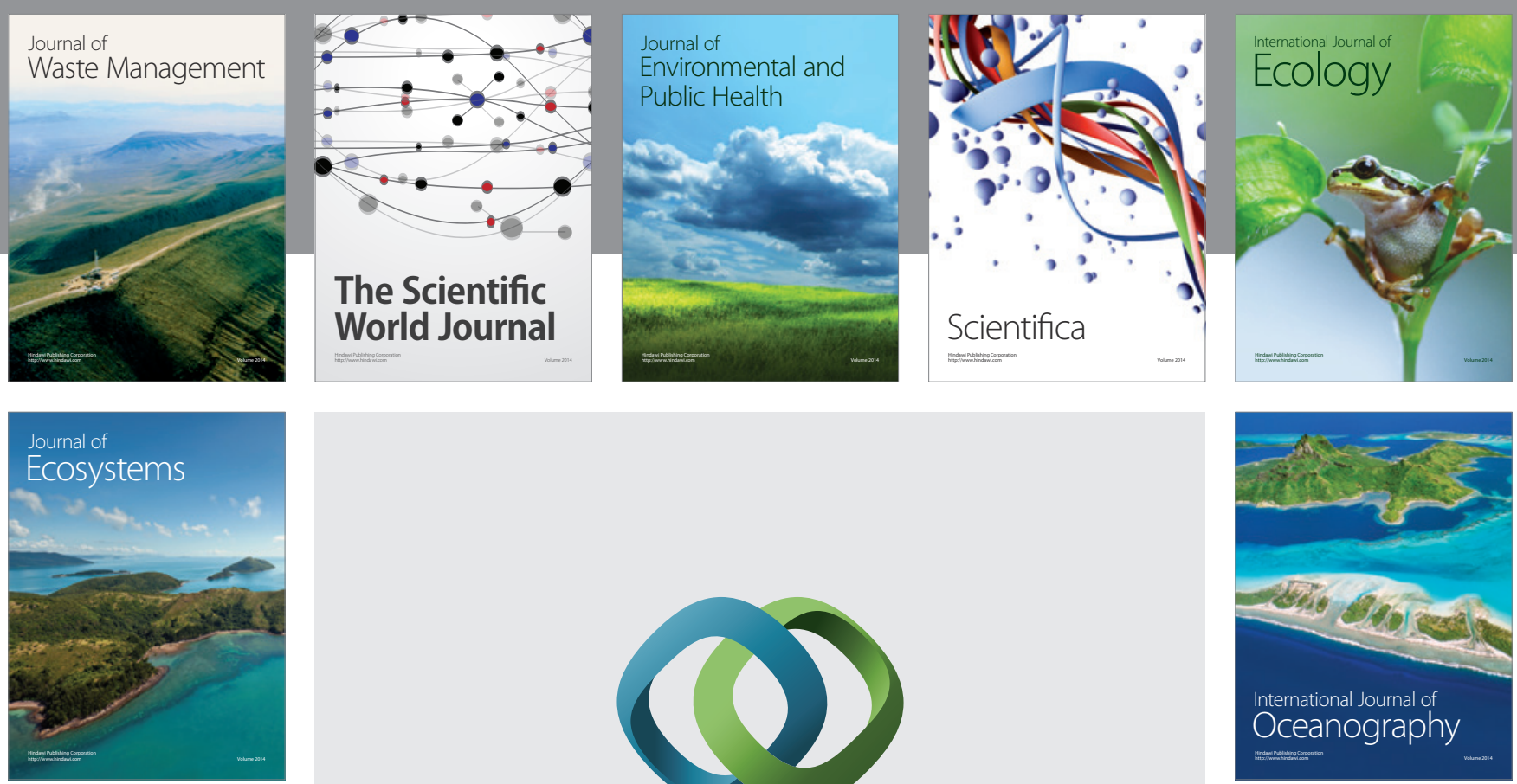

The Scientific World Journal
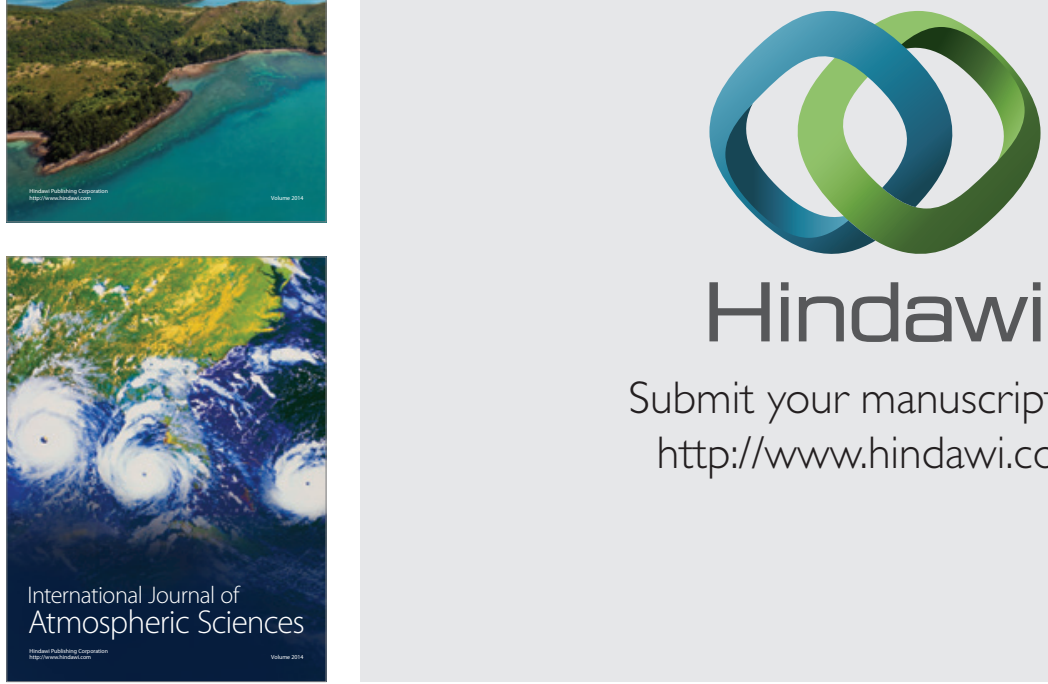

\section{Hindawi}

Submit your manuscripts at

http://www.hindawi.com
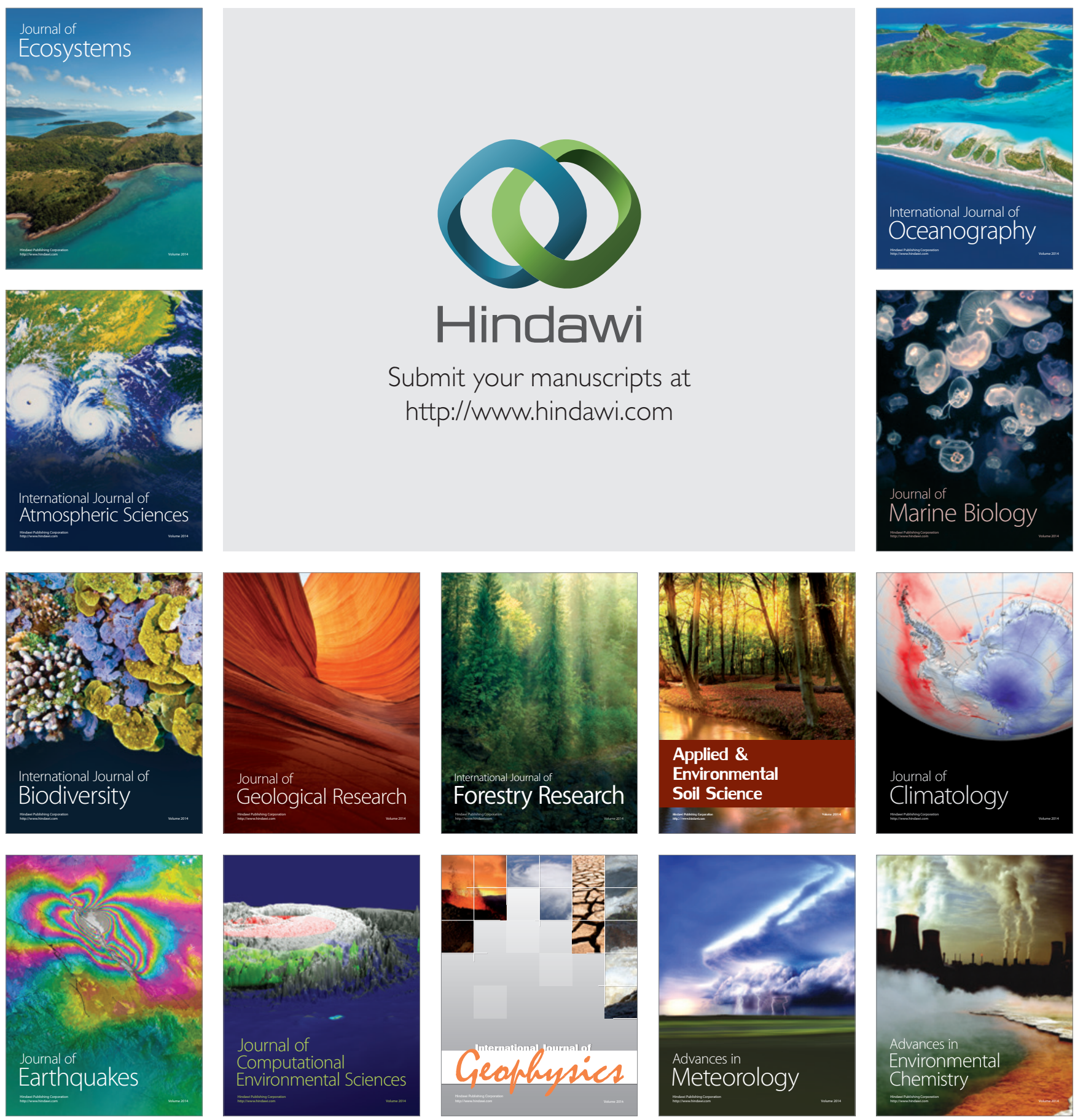